\title{
Job Satisfaction, Organizational Commitment and Stress among Offshore Oil and Gas Platform Employees
}

\author{
Haryanni Harun ${ }^{1}$, Rohani Salleh ${ }^{1}$, Mumtaz Ali Memon ${ }^{1}$, M Noor Rosli Baharom ${ }^{1} \&$ Azrai Abdullah ${ }^{1}$ \\ ${ }^{1}$ Department of Management and Humanities, Universiti Teknologi PETRONAS, Perak, Malaysia \\ Correspondence: Haryanni Harun, Department of Management and Humanities, Universiti Teknologi \\ PETRONAS, 31750 Seri Iskandar, Perak, Malaysia. E-mail: haryanniharun@petronas.com.my
}

Received: November 19, 2013

Accepted: March 19, 2014 Online Published: May 30, 2014

doi:10.5539/ass.v10n11p28

URL: http://dx.doi.org/10.5539/ass.v10n11p28

\begin{abstract}
Working offshore on an oil rig is perceived as a challenge to many people. Having to live and work at the same site, shift-work schedule with long working hours, high risks and remote work environment; are some common features of an offshore job. High job satisfaction (JS), strong organizational commitment (OC) and minimal stress (St) are key factors to retain the offshore oil and gas platform employees. This is critical to oil and gas companies as skilled and experienced employees are highly demanded in the industry. This study aimed to examine the level of job satisfaction, organizational commitment and stress among oil rig employees $(n=214)$ situated in the coast of East Malaysia. This study also analyzed the relationship between the three variables. The data was collected using a self-administered questionnaire. The findings suggested a moderate level of stress and job satisfaction, while organizational commitment was found to be quite high among the respondents. Job satisfaction was found to have significant positive association with organizational commitment, on the other hand stress was found to be negatively correlated to OC \& JS. The implications of these findings for practice and theory in the field of Human Resource Management are discussed.
\end{abstract}

Keywords: commitment, job satisfaction, stress, oil and gas

\section{Introduction}

The work environment of an offshore platform is unique, as such; employees live and work in the same confined area surrounded by nothing but the uncertain ocean. Offshore oil and gas platform employees face constant uncertainty with issues such as safety of their workplace, hazardous tasks to undertake, production demands and constant technological changes. With the challenging work environment and the nature of work involved, often, offshore jobs may not be a preferred option to many people. Recruitment and retaining offshore employees, especially the skilled and experienced ones, can be a challenge to the industry. Hence many of the oil and gas companies go out of their way to make sure their employees' time spent onboard is a favourable one.

Work performance of offshore oil and gas platform employees are crucial to the success of any oil and gas company. They are unquestionably the most vital capital and they need to be constantly motivated to be retained. Specifically, this study looks into the aspects of job satisfaction (JS), organizational commitment (OC) and Stress (St) of offshore oil and gas platform employees. Although JS, OC and St may be considered well researched topics within the area of management and organizational studies, still minimal knowledge is known about them from the perspective of oil and gas offshore platform employees. Most of the studies found on offshore oil and gas platforms were generally related to health, safety and environment (HSE) and risk management issues. The present study is therefore significant not only in contributing new knowledge in the area of management and organizational studies but also provides fresh insights into human resource management in the context of employees working on oil and gas offshore platforms. Thus, this study fills this gap. Overall, this study will also provide better understanding of the factors that may influence employees' performance and retention. The following research objectives (ROs) were set to be addressed:

1) To identify the level of JS, OC and St of the offshore oil and gas platform employees

2) To examine the relationships between JS, OC and St of offshore oil and gas platform 


\section{Literature Review}

The seminal definition of organizational commitment by Mowday, Steers, and Porter (1979) asserts that OC is "the relative strength of an individual identification with and involvement in a particular organization". Studies have shown that $\mathrm{OC}$ is one of the important aspects of understanding and predicting employees' work behavior and performance (Wright \& Kehoe, 2008). Meyer (2009) indicated that OC is related to employees' physical and psychological well-being. Hence, OC is constantly associated to employees' emotional attachment to their organizations that foster performance, lessens absenteeism and turnover (Meyer, 2009; Meyer \& Allen, 1997)

Most often, the study on OC relates highly to the study on JS. JS is defined as a person's evaluation of his or her job and work context (Saari \& Judge, 2004). Studies on JS are normally linked to organizational behaviour issues such as absenteeism, stress as well as other outcomes such as employee retention (Parisi \& Weiner, 1999; Weiner, 2000). In a comprehensive review of 301 studies, Judge, Thoresen, Bono, and Patton (2001) identified that that there is a high correlation between JS and job performance. The above reviews provide indications that JS is still undoubtedly a critical aspect of employees' workplace behaviours and deemed critical to determine their job performance.

St is a "mental or physical phenomenon formed through one's cognitive appraisal of the stimulation and is a result of one's interaction with the environment" (Lazarus \& Folkman, 1984) has a role in determining employees' performance. Working as an oil and gas offshore platform employees is well recognized as a stressful occupation (Chen, Wong, Yu, Lin, \& Cooper, 2003). The existence of St mainly depends on the existence of the stressor, and reactions toward stress differ from one individual to another. According to Chen et al. (2003, p. 288), stressors on offshore platforms would be such as "adverse physical environment, far out and rough seas, risks of travelling mode (helicopter and ship), hazardous working zones, isolation from community and the family, and the special demands and constraints inherent in offshore work, can be considered as stressors to the workers". Research indicated that high level of stress often results in negative outcomes of workplace behavior (Sutherland \& Flin, 1984). Findings by (Ahsan, Zaini, Fie, \& Alam, 2009) indicated that there was a significant negative relationship between St and JS. In addition St was also found to have a negative significant relationship with OC (Sutherland \& Flin, 1984).

\section{Method}

\subsection{Data Collection and Respondents of the Study}

The research was conducted on an offshore oil and gas platform of a Malaysian multinational company located in the coast of East Malaysia. The team of researchers was on board the platform to administer the data collection process; however the employees were given the time and freedom to respond to the survey. In addition, the research team also included observations approach in order to better understand and justify the employees' behaviours and other work-related matters.

The team went on board in two separate times to capture the employees' different work shifts. Out of the 240 sets distributed only 214 valid questionnaires were collected and analyzed. Majority of the respondents were male (97.7\%), there was only one (1) female engineer working as Operation Supervisor on this platform at the time of this study. Majority of the respondents were below 40 years old (67.5\%). 77.1\% of them are married and majority (96.5\%) had an academic qualification of certificate level and below. The respondents included permanent employees of the multinational company as well as employees of service contractors from other companies.

\subsection{Instrument}

OC was measured using items taken from Allen and Meyer (1990) specifically focused on affective commitment. For JS, the items were adapted from the Job Satisfaction Survey (JSS) scales, developed by (Spector, 1997). Stress was measured by a 10 -item scale that was developed by the researchers based on previous studies. A five-point Likert scale was used, ranging from strongly disagree (1) to strongly agree (5). In addition, some demographic questions were asked to capture the personal profile of the respondents, covering items such as gender, age group, marital status and level of education.

To ensure better understanding of the survey, a bilingual (English and Malay language) questionnaire was used for the study. This is important as the majority (95\%) of the employees were Malaysians at the support staff level where English is not their main language used. Hence, the researchers translated all the items from English to Malay and the translated draft was then checked by a linguistic specialist who is fluent in both Malay and English. This is in accordance to the back translation method suggested by (Brislin, 1980) to ensure consistency in meaning. 
Table 1 illustrates that the alpha scores ranging for the scales used. With scores ranging from 0.72 to 0.78 , all scales showed adequate reliability levels and were considered reliable to measure the variables of this study.

Table 1 . Reliability statistics

\begin{tabular}{lll}
\hline Variables & No of Items & Cronbach $\boldsymbol{\alpha}$ \\
\hline Organizational commitment & 14 & .72 \\
Job Satisfaction & 9 & .75 \\
Stress & 10 & .78 \\
\hline
\end{tabular}

\subsection{Results}

Table 2 provides the mean score, standard deviations and correlations for the three variables of this study in addressing RO1 and RO2. The following interpretations were used to analyze the mean scores and standard deviations: 4.21 to 5.00 - high, 3.41 to 4.20 - moderately high, 2.61 to 3.40 - moderate, 1.81 to 2.60 moderately low and $1.00-1.80$ as low.

Table 2. Mean scores, standard deviations and correlations

\begin{tabular}{llllll}
\hline & Mean & SD & 1 & 2 & 3 \\
\hline Job satisfaction & 3.70 & .47 & 1 & $.74^{* *}$ & $-.31^{* *}$ \\
Organizational Commitment & 3.35 & .39 & & 1 & $-.32^{* *}$ \\
Stress & 2.37 & .53 & & & 1 \\
\hline
\end{tabular}

Note: Scale 1-5, ranging from (1) strongly disagree to (5) strongly agree

** Correlation is significant at the 0.01 level (2-tailed)

As shown, the results indicated that the respondents' had a moderate level of OC (mean=3.35, $\mathrm{SD}=0.39$ ), moderately high level of JS (mean=3.70, $\mathrm{SD}=0.47$ ) and, rather unexpectedly, a moderately low level of stress (mean=2.37, $\mathrm{SD}=0.53$ ).

The results also suggested that there is a significant positive relationship between JS and OC $(p<0.01 ; r=$ $0.74^{* *}$ ), indicating that higher JS will lead to higher OC. It was also found that there was a significant negative relationship between St and OC ( $\left.p<0.01 ; \mathrm{r}=-0.32^{* *}\right)$. This showed that higher St will lead to lower OC among the employees. St was also found to have significant negative relationship with JS ( $\left.p<0.01 ; \mathrm{r}=-0.31^{* *}\right)$ indicating that higher the St, the lower employees' JS will be.

\section{Discussions of Findings}

This study was undertaken to determine the level of JS, OC and St of offshore oil and gas platform employees and the relationships between these variables. This section discuses the survey findings and provide explanation based on some literature support and on site observations.

The findings indicated that the employees had moderate level of JS. Based on the observations, the type of jobs the employees did and their workplace environment may have contributed to this finding. Being on the platform, many aspects such as tasks, rest time and leisure activities were all under the platform's ground rules, policies and procedures. For example, one will be given demerit points if caught not holding the side railing while walking down the stairs. In addition, late attendance at meetings, an immediate reminder would be issued. Nevertheless the above work behaviours are critical in this workplace especially when discipline is required in ensuring safety of each person as well as work productivity. While on board, almost all the time they must somehow report most their activities to their superiors. It was noticeable that a social gap somehow existed between the lower level employees and the executives, which consist of a Platform Supervisor, a Senior Operation Supervisor and an Operation Supervisor. Overall, the way things work on board the platform, the sets of behavioural control imposed on the employees, may have contributed to the level of JS found in this study.

OC on the other hand was found to be moderately high. The findings may be attributed to the necessary, organized works and behavioural expectations. Furthermore, working in a production-intensive company the 
employees dedicatedly deliver the everyday target set by the company, resulting in them having quite a high commitment level.

Although, as noted earlier, working on oil and gas offshore platform is well recognized as a stressful occupation, our findings rather unexpectedly showed that the employees had moderately low level of stress. This interesting finding may be due to the fact that the employees are able to manage their stress level with the facilities provided by the company. For example, relaxation and leisure facilities are available for the employees to use once they are off from their jobs. In addition, the 2-weeks working schedule followed by a 2-weeks break, may have contributed to the moderately low level of stress. The long break gives them the opportunity to de-stress hence making them more composed to face work on board the platform.

In addition, findings of this study indicated that JS is positively associated with OC. It is consistent with Wiener and Vardi (1980) and Shore and Martin (1989) contentions that organizational commitment is more closely associated with job satisfaction. When employees get positive experience with major job related factors such as nature of job, the environment itself, the variety and scope (Saari \& Judge, 2004), thereafter create a sense of obligation to be committed.

The findings also showed that St has a significant negative relationship with OC and JS. These findings are comparable with several empirical studies (Jamal, 1984; Kahn, D.M., Quinn, Snoek, \& Rosenthal, 1964). When individuals perceived their work roles are unsafe physically and psychologically, they would improbably feel dissatisfied with their jobs (Jamal, 1990). Likewise, when job became unpleasant; physically and psychologically, leads individuals to less liking their jobs. As a result, it is rational to observe less organizational loyalty and low level JS as the major consequences of higher level of stress.

\section{Limitations and Direction for Future Research}

Some limitations were identified in this study. In developing the research instruments particularly stress, we did not specifically utilize an existing scale however the scales were developed based on literature findings. Although the Cronbach alpha for the scale was considerably high $(\alpha=.78)$, we highly recommend that future researchers utilize a well validated stress scale for example the Occupational Stress Scale - OSS (Williams \& Cooper, 1998).

This study was exploratory in nature since almost no other similar study was found at the time this study was conducted. The researchers attempted into what was considered an unchartered area of research and the use of a self-administered questionnaire may have lead to information biasness. The presence of the research team may have also made the employees felt somewhat anxious and thus apprehended them from providing honest and truthful response. Future studies should take this into consideration of planning for a strategy to eliminate or at least, reduce the issue of information biasness. Also, we recommend that future research to be conducted at a few different platforms to further validate the findings.

\section{Implications and Conclusion}

Despite the limitations, the findings for this study contributed significantly to new knowledge particularly in the context of offshore oil and gas platforms in the South-east Asia region. Our findings provide practical implications relevant to the human resource management and organizational behaviour of oil and gas companies. Management of these companies may use the findings to form various strategies to effectively elevate the offshore platforms employees' job satisfaction and organizational commitment. Meanwhile, the identification of stress level allows the management of oil and gas companies to develop methods or ways to manage their employees' stress hence reducing it to make the employees perform better at work.

\section{References}

Ahsan, N., Zaini, A., Fie, D. Y. G., \& Alam, S. S. (2009). A study of job stress on job satisfaction among university staff in Malaysia: Empirical study. European Journal of Social Sciences, 8(1), 121-131.

Allen, N. J., \& Meyer, J. P. (1990). The measurement and antecedents of affective, continuance and normative commitment to the organization. Journal of occupational psychology, 63(1), 1-18. http://dx.doi.org/10.1111/j.2044-8325.1990.tb00506.x

Brislin, R. W. (1980). Translation and content analysis of oral and written material. Handbook of cross-cultural psychology, 22, 349-444.

Chen, W. Q., Wong, T. W., Yu, T. S., Lin, Y. Z., \& Cooper, C. L. (2003). Determinants of perceived occupational stress among Chinese offshore oil workers. Work and Stress, 17(4), 287-305. http://dx.doi.org/10.1080/02678370310001647302 
Jamal, M. (1984). Job stress and job performance controversy: An empirical assessment. Organizational Behavior and Human Performance, 33, 1-21. http://dx.doi.org/10.1016/0030-5073(84)90009-6

Jamal, M. (1990). Relationship of job stress and Type-A behavior to employees' job satisfaction, organizational commitment, psychosomatic health problems, and turnover motivation. Human Relations, 43, 727. http://dx.doi.org/10.1177/001872679004300802

Judge, T. A., Thoresen, C. J., Bono, J. E., \& Patton, G. K. (2001). The job satisfaction-job performance relationship: A qualitative and quantitative review. Psychological Bulletin, 127, 376-407. http://dx.doi.org/10.1037/0033-2909.127.3.376

Kahn, A. L., D.M., W., Quinn, R. P., Snoek, J. D., \& Rosenthal, R. (1964). Organizational stress. New York: John Wiley and Sons.

Lazarus, R. S., \& Folkman, S. (1984). Stress, appraisal, and coping. New York: Springer.

Meyer, J. P. (Ed.). (2009). Commitment in a Changing World of Work. New York: Taylor \& Francis Group.

Meyer, J. P., \& Allen, N. J. (1997). Commitment in the Workplace. Theory, Research and Application. California: SAGE Publications.

Mowday, R. T., Steers, R. M., \& Porter, L. W. (1979). The Measurement of Organizational Commitment. Journal of Vocational Behavior, 14, 224-247. http://dx.doi.org/10.1016/0001-8791(79)90072-1

Parisi, G. A., \& Weiner, S. P. (1999). Retention of employees: Country-specific analyses in a multinational organization. Paper presented at the Fourteenth Annual Conference of the Society for Industrial and Organizational Psychology, Atlanta.

Saari, L. M., \& Judge, T. A. (2004). Employee attitudes and job satisfaction. Human Resource Management, 43(4), 395-407. http://dx.doi.org/10.1002/hrm.20032

Shore, L. M., \& Martin, H. J. (1989). Job Satisfaction and organizational commitment in relation to work performance and turnover intention. Human Relation, 42(7), 625-638. http://dx.doi.org/10.1177/001872678904200705

Spector, P. E. (1997). Job satisfaction: Application, assessment, causes, and consequences (3rd ed.). SAGE.

Sutherland, V. J., \& Flin, R. H. (1984). Stress at sea: a review of working conditions in the offshore oil and fishing industries. Work Stress, 3, 269-285. http://dx.doi.org/10.1080/02678378908251563

Weiner, S. P. (2000). Worldwide technical recruiting in IBM: Research and action. Paper presented at the Attracting and keeping top talent in the high-tech industry: Practitioner Forum at the Fifteenth Annual Conference of the Society for Industrial and Organizational Psychology, LA.

Wiener, Y., \& Vardi, Y. (1980). Relationships between job, organization and career commitment and work outcomes-an integrative approach. Organizational Behavior and Human Performance, 26, 81-96. http://dx.doi.org/10.1016/0030-5073(80)90048-3

Williams, S., \& Cooper, C. L. (1998). Measuring occupational stress: Development of the pressure management indicator. Journal of Occupational Health Psychology, 3(4), 306. http://dx.doi.org/10.1037/1076-8998.3.4.306

Wright, P. M., \& Kehoe, R. R. (2008). Human resource practices and organizational commitment: A deeper examination. Asia Pacific Journal of Human Resources, 46, 16-20. http://dx.doi.org/10.1177/1038411107086540

\section{Copyrights}

Copyright for this article is retained by the author(s), with first publication rights granted to the journal.

This is an open-access article distributed under the terms and conditions of the Creative Commons Attribution license (http://creativecommons.org/licenses/by/3.0/). 